\title{
ANALISIS KEBUTUHAN KONSUMEN DALAM PENGEMBANGAN JENANG DENGAN METODE FUZZY QUALITY FUNCTION DEPLOYMENT (FQFD) \\ [Analysis of Consumer Needs for Jenang Development with Fuzzy Quality Function Deployment (FQFD) Method]
}

\author{
Mas'ud Effendi*, Luluk Mei Arifa, dan Siti Asmaul Mustaniroh \\ Jurusan Teknologi Industri Pertanian, Fakultas Teknologi Pertanian, \\ Universitas Brawijaya \\ Jl. Veteran Malang 65145 Jawa Timur Indonesia \\ *Email Korespondensi: mas.ud@ub.ac.id \\ Diterima : 29 September 2017 \\ Disetujui : 30 Januari 2018
}

\begin{abstract}
UD. Bu Sulasmi is one of the business units that produce jenang in Blitar regency. The problem of the company was the marketing activity that has not been maximally indicated by the low sales of jenang which was $60 \%$ of the expected target. The low sales of jenang was due to competition with other jenang entrepreneurs. The purpose of this study was to determine the priority needs of consumers and improvements that need to be done by the company in increasing sales of jenang. The method used in this research was Fuzzy Quality Function Deployment (FQFD). The result of research indicated that attribute which become priority of consumer requirement were list of expiration date with a value of 0.0796 , packaging design with a value of 0.0714 , and accuracy of net weight of jenang with information contained in packaging with a value of 0.0665 . Improvements that can be done by the company was to design a more attractive packaging design by including quality information on the packaging.
\end{abstract}

Keywords: jenang, needs, quality.

\begin{abstract}
ABSTRAK
UD. Bu Sulasmi adalah salah satu unit usaha yang memproduksi jenang di Kabupaten Blitar. Permasalahan perusahaan adalah kegiatan pemasaran yang belum maksimal yang ditunjukan dengan hasil penjualan jenang yang masih rendah yaitu $60 \%$ dari target yang diharapkan. Rendahnya penjualan jenang dikarenakan persaingan dengan pengusaha jenang lainnya. Tujuan penelitian ini adalah untuk menentukan prioritas kebutuhan konsumen serta perbaikan yang perlu dilakukan oleh perusahaan dalam meningkatkan penjualan jenang. Metode yang digunakan dalam penelitian ini adalah Fuzzy Quality Function Deployment (FQFD). Hasil penelitian menunjukkan bahwa atribut yang menjadi prioritas kebutuhan konsumen adalah tercantumnya tanggal kadaluwarsa dengan nilai 0.0796, desain kemasan dengan nilai 0.0714 , dan kesesuaian berat bersih jenang dengan informasi yang tertera pada kemasan dengan nilai 0.0665 . Perbaikan yang dapat dilakukan oleh perusahaan adalah dengan melakukan perancangan desain kemasan yang lebih menarik dengan mencantumkan informasi kualitas pada kemasan.
\end{abstract}

Kata kunci: jenang, kebutuhan, kualitas

\section{PENDAHULUAN}

Jenang merupakan makanan tradisional di Indonesia, khususnya di daerah Jawa. Kabupaten Blitar merupakan salah satu kabupaten di Pulau Jawa yang terletak di Propinsi Jawa Timur dan saat ini menjadi salah satu sentral pembuatan jenang dan makanan tradisional lainnya. Hal ini didukung dari adanya produksi gula kelapa cetak melimpah yang 
merupakan bahan baku dalam pembuatan jenang. Menurut Mulyadi (2011), Blitar merupakan pusat dari pembuatan gula kelapa cetak terbesar di Propinsi Jawa Timur dengan jumlah usaha mencapai 8.980 unit. Produsen jenang di Kabupaten Blitar juga banyak, yaitu mencapai 12 unit dengan rata-rata produksi 5 kwintal per hari dan dipasarkan di berbagai wilayah di Kabupaten Blitar dan sekitarnya (Anonim, 2013). Salah satu usaha memproduksi jenang yang sudah dikenal di pasaran adalah Unit Dagang (UD) Bu Sulasmi.

UD. Bu Sulasmi merupakan usaha yang bergerak dalam bidang industri makanan kecil sejak tahun 1986 dengan produk utamanya geti, terletak di Kecamatan Kademangan, Kabupaten Blitar. Seiring berjalannya waktu, usaha ini mulai melakukan diversifikasi produk dengan memproduksi jenang guna meningkatkan volume penjualan. Permasalahan yang saat ini dihadapi oleh UD. Bu Sulasmi adalah kegiatan pemasaran yang belum sepenuhnya maksimal jika dilihat dari hasil penjualan jenang yang masih rendah yaitu hanya mencapai $60 \%$ dibandingkan dengan geti. Rendahnya penjualan jenang dikarenakan banyaknya pesaing sehingga menimbulkan persaingan yang ketat dalam memperoleh konsumen, sedangkan jenang dari UD. Bu Sulasmi hanya dipasarkan di outlet serta menerima pesanan. Langkah awal yang perlu dilakukan oleh UD. Bu Sulasmi adalah memperbaiki sekaligus meningkatkan kualitas jenang. Kegiatan pengembangan produk dilakukan agar produk tersebut mampu memenuhi tuntutan pasar dan selera konsumen (Tutuhatunewa, 2010).

Beberapa metode yang dapat digunakan dalam manajemen kualitas adalah Six Sigma, Quality Function Deployment (QFD), Statistical Process Control (SPC), Acceptance Sampling, dan
Service Quality (ServQual). Metode yang dipilih adalah Fuzzy Quality Function Deployment (FQFD). FQFD merupakan gabungan dari metode Fuzzy dan QFD, karena mampu memperjelas ketidakpastian dalam menerjemahkan keinginan konsumen ke dalam desain produk. Hal ini diperlukan karena keinginan konsumen bersifat kualitatif dan subyektif. Metode QFD dipilih karena metode ini mampu menerjemahkan kebutuhan konsumen ke dalam sebuah produk guna memperbaiki maupun mengembangkan produk sesuai dengan kebutuhan konsumen. Metode QFD merupakan suatu cara yang digunakan untuk mengetahui secara langsung apa yang harus dilakukan oleh perusahaan untuk memenuhi kebutuhan konsumen serta mampu menerjemahkan kebutuhan konsumen ke dalam syarat teknis yang diprioritaskan (Andayani et al., 2015). Menurut Liu (2009), logika Fuzzy merupakan sebuah logika ang memiliki nilai kekaburan atau kesamaran antara dua nilai dalam sistem yang sederhana. Tujuan penelitian ini adalah menentukan kebutuhan konsumen serta prioritas perbaikan yang perlu diterapkan oleh UD. Bu Sulasmi dalam usaha mengembangkan produk jenang merek "Kuda Terbang".

\section{METODE PENELITIAN}

Penelitian ini dilaksanakan di UD. $\mathrm{Bu}$ Sulasmi yang berlokasi di Desa Rejowinangun Rt. 02 Rw. 02, Kecamatan Kademangan, Kabupaten Blitar pada bulan Februari-Maret 2017. Penelitianini berdasarkan pada persepsi konsumen jenang UD. $\mathrm{Bu}$ Sulasmi. Penelitian berfokus pada kualitas produk.Metode yang digunakan adalah FQFD sampai pada tahap planning matrix dengan bantuan triangular fuzzy number. Perusahaan pesaing yang dipilih adalah 
Omah Jenang. Pengolahan data hasil penelitian dilakukan di laboratorium Manajemen Agroindustri, Jurusan Teknologi Industri Pertanian, Fakultas Teknologi Pertanian, Universitas Brawijaya, Malang.

Penentuan responden menggunakan non probability sampling dengan teknik purposive sampling, dimana teknik tersebut digunakan untuk menetapkan jumlah sampel dengan cara memilih sampel yang dikehendaki oleh peneliti (Nursalam, 2008). Responden yang mengisi kuesioner adalah konsumen yang pernah mengonsumsi jenang minimal sekali dalam kurun waktu sebulan terakhir yang ditemui di outlet UD. Bu Sulasmi serta berusia 17-60 tahun. Penentuan jumlah sampel berdasarkan rumus linear time function, karena jumlah populasi tidak diketahui secara pasti (Nurkhasanah et al., 2011) dengan rumus:

$\mathrm{n}=\frac{\mathrm{T}-\mathrm{t}_{0}}{\mathrm{t}_{1}}=\frac{150-120}{0,5}=60$ sampel

Keterangan:

$\mathrm{n}=$ jumlah sampel

$\mathrm{T}=$ waktu yang tersedia untuk penelitian $=(30$ hari $\times 5$ jam $)=150$ jam

$\mathrm{t}_{0}=$ waktu tetap tidak tergantung pada besarnya sampel, yaitu waktu pengambilan sampel $=(4 \mathrm{jam} / \mathrm{hari} \mathrm{x}$ 30 hari) $=120$ jam

$\mathrm{t}_{1}=$ waktu yang digunakan responden untuk mengisi kuesioner $(0,5$ $\mathrm{jam} / \mathrm{kuesioner}$ )

\section{Analisis Data}

Tahapan pengolahan data menggunakan Fuzzy QFD level I adalah sebagai berikut (Wawolumaja dan Rudianto, 2012).

1. Pembuatan kebutuhan konsumen (Voice of Customer).
2. Pembuatan matriks perencanaan meliputi:

a. Penentuan bobot kriteria menggunakan Triangular Fuzzy Number (TFN).TFN digunakan karena dianggap lebih mudah dalam perhitungan (Kahraman et al., 2012). Konversi penilaian linguistik kedalam bilangan fuzzy dapat dilihat pada Tabel 1. Proses defuzzifikasi menggunakan rumus $\frac{a+b+c}{3}$ dimana a merupakan batas bawah, $b$ nilai tengah, dan c batas atas (Chan et al., 1999).

b. Penentuan Importance to Customer (ItC) - diperoleh dari hasil kuesioner tingkat kepentingan.

c. Consumer Satisfaction Performance (CuSP) dan Competitive Satisfaction Performance (CoSP) diperoleh dari hasil kuesioner tingkat kepuasan.

d. Goal - perbandingan nilai terbaik tingkat kepuasan konsumen jenang perusahaan dengan pesaing.

e. Improvement Ratio (IR) menentukan tingkatan yang ingin dicapai perusahaan untuk memenuhi kebutuhan konsumen.

$$
\mathrm{IR}=\frac{\text { Goal }}{C u S P}
$$

f. Sales Point - menunjukkan seberapa besar pengaruh pemenuhan kebutuhan konsumen terhadap penjualan produk.

g. Raw Weight dan Normalized Raw Weight (NRW) - Raw weight menunjukkan kepentingan akhir konsumen.

Raw Weight $=$ ItC x IR x Sales Point

h. Nilai NRW menunjukkan pentingnya nilai Raw Weight dibandingkan dengan nilai Raw Weight Total. 


$$
\mathrm{NRW}=\frac{\text { Raw Weight }}{\text { Raw Weight Total }}
$$

3. Pembuatan Respon Teknis - tanggapan dari produsen yang akan digunakan dalam merespon kebutuhan konsumen.

4. Penentuan Relationship - penentuan hubungan yang terjadi antara kebutuhan konsumen dengan respn teknis. Simbol yang digunakan dapat dilihat pada Tabel 2.

5. Penentuan Korelasi Teknismenggambarkan hubungan dan ketergantungan antar respon teknis.
Hubungan dari masing-masing respon teknis dapat diberi simbol berdasarkan tingkat hubungannya, seperti (++) hubungan positif kuat, (+) hubungan positif lemah, (x) hubungan negatif lemah, (xx) hubungan negatif kuat, dan ( ) tidak ada hubungan.

6. Pembuatan Prioritas Respon Teknis menentukan prioritas perbaikan pada respon teknis.

7. Benchmarking dan Target membandingkan kinerja respon teknis perusahaan dan pesaing serta menentukan target yang ingin dicapai perusahaan.

Tabel 1.Konversi Penilaian Linguistik ke dalam Bilangan Fuzzy.

\begin{tabular}{lcc}
\hline \multicolumn{1}{c}{$\begin{array}{c}\text { Skala Linguistik Tingkat } \\
\text { Kepentingan }\end{array}$} & Skala Likert & Skala Bilangan Fuzzy \\
\hline Sangat Tidak Penting & 1 & $(1,1,2)$ \\
Tidak Penting & 2 & $(1,2,3)$ \\
Cukup Penting & 3 & $(2.3 .4)$ \\
Penting & 4 & $(3,4,5)$ \\
Sangat Penting & 5 & $(4,5,5)$ \\
\hline
\end{tabular}

Sumber: Kiswanto et al. (2013)

Metode penelitian memuat penjelasan secara lengkap mengenai alat dan bahan penelitian, waktu/tempat penelitian, metode atau rancangan percobaan/survei dalam pengumpulan dan analisa data. Metode yang kurang lazim ditulis secara rinci berikut rujukannya.

Tabel 2. Simbol Kekuatan Hubungan

\begin{tabular}{llc}
\hline Simbol & \multicolumn{1}{c}{ Keterangan } & Nilai \\
\hline & Tidak ada hubungan & 0 \\
& Hubungan lemah & 1 \\
& Hubungan moderat & 3 \\
& Hubungan kuat & 9 \\
\hline Sumber: & Wawolumaja dan & Rudianto \\
& (2012) &
\end{tabular}

\section{HASIL DAN PEMBAHASAN}

\section{Gambaran Umum Perusahaan}

Usaha Dagang (UD) Bu Sulasmi merupakan salah satu unit usaha di Kabupaten Blitar yang bergerak dalam bidang industri makanan. Usaha ini didirikan oleh Ibu Sini (Almh) pada tahun 1986 yang berlokasi di Desa Rejowinangun Rt. 02 Rw 02, Kecamatan Kademangan, Kabupaten Blitar. Pada awal berdiri usaha ini berupa industri rumahan dengan nama Geti Kuda Terbang yang hanya memproduksi satu produk saja, yaitu geti. Seiring dengan perkembangan bisnisnya, pada tahun 2002 usaha ini berubah menjadi Usaha Dagang (UD) dengan nama Bu Sulasmi yang dikelola oleh Ibu Sulasmi dibantu 
oleh anak dan menantunya. Hingga saat ini produk yang dihasilkan berkembang menjadi 12 produk, yaitu geti, jenang ketan atau yang biasa disebut jenang, jenang tape, kacang pedas, madumongso, wajik kletik, sambal pecel, matari, kue kering, sitru asem, opak gambir, dan undruk yuyu. Tenaga kerja yang dimiliki berjumlah 15 orang. UD. Bu Sulasmi telah memperoleh ijin pendirian usaha dan dagang dengan nomor P-IRT.

\section{Proses Produksi Jenang}

Secara singkat proses produksi jenang sebagai berikut:

1. Sortasi - memilih ketan yang berkualitas baik dan menghilangkan ketan yang rusak serta tidak layak pakai dengan cara pemilihan secara manual (Nusa et al., 2012).

2. Perendaman - digunakan untuk melunakkan ketan sehingga mudah untuk dihancurkan (Murni et al., 2015).

3. Penggilingan - penghancuran ketan menjadi tepung ketan (Murni et al., 2015).

4. Pembuatan santan - kelapa diperas dan ditambahkan air sehingga dihasilkan santan (Nusa et al., 2012).

5. Pemasakan -santan dimasak hingga menjadi minyak, kemudian gula merah dimasukkan ke dalam jedi hingga larut dan mengental. Selanjutnya adonan tepung ketan dimasukkan dan ditambahkan garam secukupnya sambil terus diaduk selama 3-4 jam pada suhu $80^{\circ} \mathrm{C}$ (Murni et al., 2015).

6. Pendinginan dilakukan agar memudahkan pengemasan (Nusa et al., 2012).

7. Pengemasan - pembungkusan jenang menggunakan besek dengan berat 1 kg/besek (Murni et al., 2015).

\section{Karakteristik Responden}

Karakteristik umum responden dalam penelitian ini dapat ditunjukkan dari jenis kelamin, usia, pekerjaan, total penghasilan atau uang saku per bulan, dan frekuensi pembelian. Jenis kelamin paling dominan adalah perempuan dengan nilai 71,67\%. Astuti (2013) menyebutkan bahwa perempuan cenderung lebih konsumtif dibandingkan dengan laki-laki. Usia paling dominan konsumen jenang adalah usia 35-43 tahun dengan nilai $28,33 \%$. Jenis pekerjaan tertinggi terdiri dari ibu rumah tangga, buruh harian, dan guru honorer dengan nilai 46,66\%, sedangkan penghasilan konsumen yang paling dominan yaitu < Rp. 750.000 dengan nilai $58,33 \%$. Jenis pekerjaan seseorang akan mempengaruhi barang dan jasa yang dibelinya, dan penghasilan yang dimiliki konsumen menunjukkan tingkat daya beli konsumen (Latief, 2011). Frekuensi konsumsi jenang dalam sebulan terakhir adalah 1 kali dengan nilai $83,33 \%$.

\section{Uji Validitas dan Reliabilitas}

Uji validitas dan reliabilitas digunakan untuk mengetahui sejauh mana kuesioner yang digunakan mampu mengukur apa yang ingin diukur serta mampu mengukur keandalan kuesioner dan konsistensi responden dalam memberikan penilaian pada setiap atribut, sehingga diharapkan hasil analisisnya dapat lebih akurat dan terpercaya. Kuesioner dinyatakan valid jika nilai $r_{\text {hitung }}>r_{\text {tabel }}(0,2542)$ (Saidani dan Arifin, 2012). Kuesioner dinyatakan reliabel ketika nilai Cronbach's Alpha > 0,6 (Yunal dan Indrayani, 2013). Berdasarkan uji validitas dan reliabilitas kuesioner dinyatakan valid dan reliabel. 


\section{Analisis FQFD Level I}

Tahapan analisis data menggunakan FQFD adalah sebagai berikut:

1. Identifikasi Kebutuhan Konsumen

Identifikasi kebutuhan konsumen ditentukan dengan wawancara kepada konsumen dan diperkuat dengan studi literatur, sehingga menghasilkan atribut kebutuhan konsumen.

2. Pembuatan Matriks Perencanaan Penentuan Importance to Customer (ItC)

Importance to Customer (ItC) merupakan persepsi konsumen tentang seberapa penting masing-masing atribut terhadap kebutuhan konsumen (Suryaningrat et al., 2010). Nilai kepentingan disusun dari nilai terbesar yang menunjukkan atribut penting bagi konsumen saat mengkonsumsi jenang. Ringkasan nilai ItC dari setiap atribut dapat dilihat pada Tabel 3. Berdasarkan nilai ItC dapat diketahui bahwa atribut yang paling diprioritaskan adalah tercantumnya tanggal kadaluwarsa, sedangkan atribut yang memiliki prioritas rendah adalah layanan keluhan. Pencantuman informasi umur simpan menjadi sangat penting karena terkait dengan keamanan produk pangan serta memberikan jaminan mutu pada saat produk hingga produk sampai ke tangan konsumen (Harris dan Fadli, 2014).

Nilai Customer Satisfaction Performance (CuSP) dan Competitive Satisfaction Performance (CoSP)

Customer Satisfaction Performance (CSP) adalah persepsi seberapa besar suatu produk mampu memenuhi kebutuhan konsumen (Suryaningrat et al., 2010). Nilai ini didapatkan dari hasil kuesioner tingkat kepuasan kemudian mengalami proses fuzzifikasi seperti nilai kepentingan kebutuhan konsumen. Ringkasan perhitungan ItC, CuSP, CoSP, Goal, IR, RW, dan NRW dapat dilihat pada Tabel 3.

Perbandingan nilai ItC dengan CuSP pada Tabel 3 menunjukan bahwa kepuasan perusahaan belum mampu memenuhi nilai kepentingan pada kebutuhan konsumen. Hal ini terlihat dari beberapa nilai CuSP yang belum mencapai angka 3 (skala likert) yang berarti cukup puas. Jika dilihat dari urutan prioritas atribut kepentingan konsumen, perusahaan belum menerapkan strategi berdasarkan kebutuhan konsumen. Hal ini terlihat dari prioritas tertinggi pada kebutuhan konsumen adalah tercantumnya tanggal kadaluwarsa, sedangkan kepuasan tertinggi pada produk perusahaan adalah jenang tidak rusak sampai ke tangan konsumen. Berbeda dengan strategi yang ditetapkan oleh pesaing, dimana pesaing telah menerapkan strategi berdasarkan kebutuhan konsumen, sehingga nilai atribut tercantumnya tanggal kadaluwarsa memiliki nilai kepuasan tertinggi. Ketidaksinkronan antara kebutuhan konsumen dan strategi yang diterapkan konsumen menyebabkan nilai CuSP lebih rendah dari CoSP. 
Tabel 3. Importance to Customer

\begin{tabular}{|c|c|c|c|c|c|c|c|c|}
\hline No. & Atribut & $\mathrm{ItC}$ & $\mathrm{CuSP}$ & CoSP & Goal & IR & $R W$ & $N R W$ \\
\hline 1 & Tekstur jenang (CR1) & 4,01 & 3,03 & 3,94 & 3,94 & 1,30 & 7,82 & 0,0572 \\
\hline 2 & Rasa jenang (CR2) & 4,03 & 3,19 & 3,78 & 3,78 & 1,19 & 7,19 & 0,0526 \\
\hline 3 & Aroma jenang (CR3) & 3,66 & 3,38 & 3,73 & 3,73 & 1,10 & 6,04 & 0,0441 \\
\hline 4 & $\begin{array}{l}\text { Kelengkapan informasi pada } \\
\text { kemasan (CR4) }\end{array}$ & 4,01 & 2,77 & 3,95 & 3,95 & 1,43 & 8,60 & 0,0629 \\
\hline 5 & $\begin{array}{l}\text { Tanpa penggunaan bahan } \\
\text { tambahan makanan sintetis } \\
\text { (pengawet, pemanis, pewarna) } \\
\text { (CR5) }\end{array}$ & 4,13 & 3,30 & 3,37 & 3,37 & $1,02^{\cdots \cdots}$ & 6,32 & 0,0462 \\
\hline 6 & $\begin{array}{l}\text { Jenang tidak rusak sampai ke } \\
\text { tangan konsumen (CR6) }\end{array}$ & 4,01 & 3,54 & 3,88 & 3,88 & 1,10 & 6,62 & 0,0484 \\
\hline 7 & Kebersihan jenang (CR7) & 4,19 & 3,10 & 3,98 & 3,98 & 1,28 & 8,04 & 0,0588 \\
\hline 8 & $\begin{array}{l}\text { Kesesuaian berat bersih jenang } \\
\text { dengan informasi yang tertera } \\
\text { pada kemasan (CR8) }\end{array}$ & 3,84 & 2,45 & 3,86 & 3,86 & 1,58 & 9,10 & 0,0665 \\
\hline 9 & $\begin{array}{l}\text { Kesesuaian harga dengan } \\
\text { kualitas (CR9) }\end{array}$ & 4,25 & 3,32 & 3,44 & 3,44 & 1,04 & 6,63 & 0,0485 \\
\hline 10 & $\begin{array}{l}\text { Tercantumnya tanggal } \\
\text { kadaluwarsa (CR10) }\end{array}$ & $4,48^{\prime \prime}$ & 2,54 & 4,11 & 4,11 & $1,62^{\circ}$ & 10,89 & $0,0796^{\circ}$ \\
\hline 11 & $\begin{array}{l}\text { Munculnya jamur sebelum } \\
\text { tanggal kadaluwarsa (CR11) }\end{array}$ & 3,85 & 3,22 & 3,53 & 3,53 & 1,10 & 6,35 & 0,0464 \\
\hline 12 & Warna jenang (CR12) & 3,48 & 3,48 & 3,64 & 3,64 & 1,05 & 5,48 & 0,0401 \\
\hline 13 & Bentuk sajian jenang (CR13) & 3,76 & 2,67 & 3,89 & 3,89 & 1,46 & 8,23 & 0,0602 \\
\hline 14 & Desain kemasan (CR14) & 4,07 & 2,50 & 3,99 & 3,99 & 1,60 & 9,77 & 0,0714 \\
\hline 15 & Kepopuleran merek (CR15) & 3,10 & 2,83 & 3,17 & 3,17 & 1,12 & 5,21 & 0,0381 \\
\hline 16 & Legalitas produk (CR16) & 3,60 & 3,25 & 3,45 & 3,45 & 1,06 & 5,72 & 0,0418 \\
\hline 17 & $\begin{array}{l}\text { Kemudahan penggunaan } \\
\text { kemasan (CR17) }\end{array}$ & 3,82 & 3,15 & 3,62 & 3,62 & 1,15 & 6,59 & 0,0482 \\
\hline 18 & $\begin{array}{l}\text { Kemudahan penyimpanan } \\
\text { (CR18) }\end{array}$ & 3,77 & 3,05 & 3,87 & 3,87 & 1,27 & 7,18 & 0,0525 \\
\hline 19 & Layanan konsumen (CR19) & 3,03 & 2,25 & 2,25 & 2,50 & 1,11 & 5,04 & 0,0369 \\
\hline
\end{tabular}

Keterangan: $\left(^{*}\right)=$ Nilai Tertinggi, $\left({ }^{* *}\right)=$ Nilai Terendah

Sumber: Data Primer Diolah (2017

Pada Tabel 3 dapat diketahui pula bahwa nilai CuSP dari masing-asing atribut masih bernilai rendah jika dibandingkan dengan nilai CoSP. Hal tersebut membuktikan bahwa responden merasa bahwa kinerja perusahaan belum mencapai apa yang diinginkan, sehingga responden memberikan nilai yang lebih rendah. Oleh karena itu, perlu dilakukan perbaikan pada masing-masing atribut agar jenang dari UD. Sulasmi mampu memuaskan konsumennya. Evaluasi dengan pihak pesaing berfungsi untuk mengetahui penilaian konsumen terhadap produk yang dihasilkan perusahaan dibandingkan dengan poduk pesaingnya (Jaelani, 2012). 


\section{Penentuan Nilai Goal dan IR}

Nilai goal merupakan nilai yang didapat dari perbandingan kepuasan perusahaan dan juga pesaing kemudian dipilih nilai yang terbesar diantara keduanya (Maulida et al., 2013). Nilai Improvement Ratio (IR) merupakan nilai yang mengindikasikan seberapa besar perusahaan perlu melakukan upaya perbaikan untuk bisa mencapai tujuan perusahaan (Kosasih et al., 2013). Ringkasan nilai goal dan IR dapat dilihat pada Tabel 3. Berdasarkan Tabel3, dapat diketahui nilai goal didapatkan dari nilai CoSP, karena nilai tersebut lebih tinggi. Nilai IR pada semua atribut lebih dari 1 yang artinya semua atribut perlu dilakukan perbaikan. Menurut Zagloel dan Nurcahyo (2013), semakin besar nilai IR maka akan semakin besar pula usaha yang dilakukan untuk perbaikan, sehingga akan sangat berguna untuk mencapai target atau tujuan perusahaan yang telah ditentukan.

\section{Sales point}

Penentuan sales point bertujuan untuk memberikan penilaian terhadap atribut mana yang perlu mendapat tindakan perbaikan dalam usaha meningkatkan kemampuan persaingan pada suatu produk (Zagloel dan Nurcahyo, 2013). Nilai sales point diperoleh dengan cara memberikan nilai 1,$5 ; 1,2$; dan 1 dengan ketentuan jika nilai ItC $=2$ nilainya 1 , untuk $2<\mathrm{ItC} \leq 3$ nilainya 1,2 dan untuk ItC $>3$ nilainya adalah 1,5 (Wawolumaja dan Rudianto, 2012). Nilai ItC yang diperoleh $>3$, maka nilai sales point ditetapkan menjadi 1,5.

\section{Raw Weight dan Normalized Raw Weight}

Raw weight (RW) merupakan besarnya bobot untuk tiap baris atribut konsumen yang menjadi dasar evaluasi terhadap penentuan prioritas pemenuhan kebutuhan konsumen (Efendi, 2007). Nilai Normalized Raw Weight (NRW) menunjukkan pentingnya nilai raw weight secara keseluruhan (Wawolumaja dan Rudianto, 2012). Nilai RW dan NRW dapat dilihat pada Tabel 3. Berdasarkan Tabel 3 dapat diketahui bahwa nilai RW dan NRW tertinggi adalah tercantumnya tanggal kadaluwarsa, desain kemasan, dan kesesuaian berat bersih jenang dengan informasi yang tertera pada kemasan. Atribut tertinggi menunjukkan prioritas yang perlu diperhatikan dan dilakukan perbaikan (Liu, 2009).

\section{Penentuan Relationship}

Pada tahap penentuan hubungan antara kebutuhan konsumen (VoC) dengan respon teknis ini dibutuhkan wawancara dengan pihak perusahaan. Tahap ini diperlukan untuk mengetahui apakah ada hubungan antara kebutuhan konsumen dengan respon teknis dan seberapa kuat/tinggi hubungan antara keduanya (Maulida et al., 2013). Hubungan tersebut disusun dalam bentuk matriks.

\section{Penentuan Korelasi Teknis}

Korelasi teknis digunakan untuk mengidentifikasi dimana masing-masing respon teknis saling mendukung atau tidak di dalam perencanaan perbaikan. (Andayani et al., 2015). Hubungan ini ditentukan dan diperoleh melalui kuesioner dan wawancara dengan pihak UD. Bu Sulasmi. Hubungan antar respon teknis pada penelitian ini ditunjukkan pada Gambar 1. 


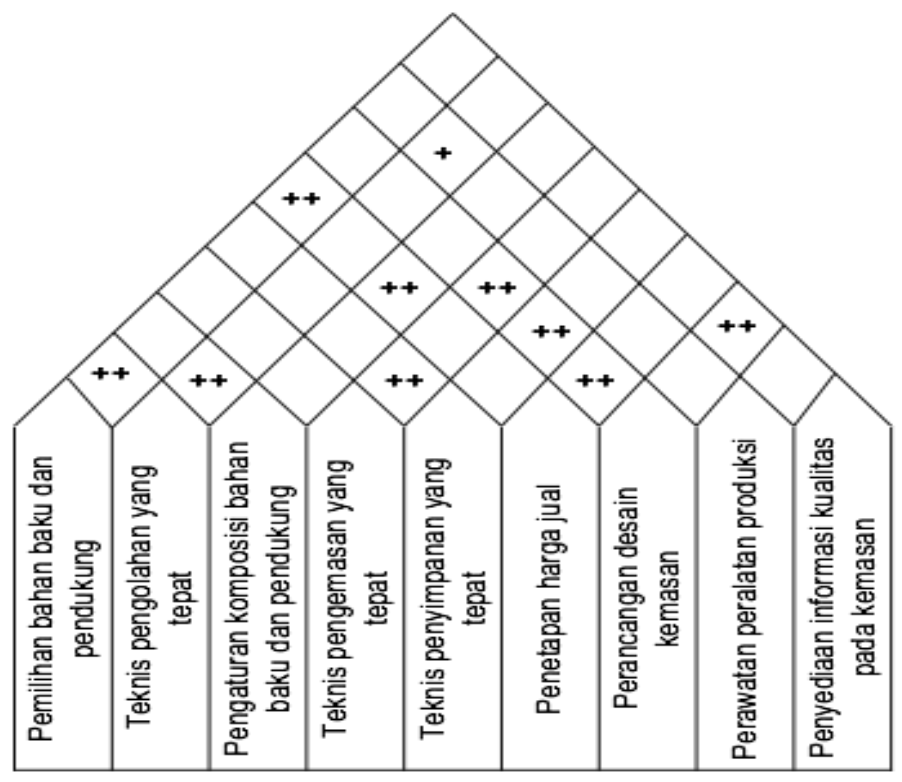

Gambar 1. Korelasi Antar Respon Teknis

\section{Bobot Respon Teknis dan Prioritas}

Penentuan prioritas didasarkan pada bobot respon teknis yang diurutkan mulai dari nilai bobot respon teknis paling tinggi sampai paling rendah. Nilai ini didapatkan dari nilai masing-masing relationship yang dikalikan dengan nilai raw weight. Menurut Chen (2007), pelayanan yang efektif harus sesuai dengan urutan prioritas dari respon teknis. Urutan prioritas dapat dilihat pada Tabel 4, dimana prioritas respon teknis yang paling tinggi adalah perancangan desain kemasan. Menurut Syamsudin et al. (2015), produk yang dihasilkan sebaiknya dibuat dengan desain kemasan yang menarik, mencantumkan informasi nama produk, nama perusahaan, berat bersih, tanggal kadaluwarsa, komposisi, kandungan nutrisi, SNI, HACCP, dan label halal.

\section{Benchmarking dan Target}

Benchmarking merupakan ukuran tingkat performansi dari respon teknis yang digunakan sebagai perbandingan kinerja respon teknis (Suryaningrat et al., 2010). Penentuan benchmarking dilakukan dengan membandingkan nilai benchmarking dari UD. Bu Sulasmi dan Omah jenang. Setelah dibandingkan, nilai yang terbaik di antara keduanya akan digunakan sebagai target untuk dilakukan perbaikan oleh perusahaan. Nilai target yang diperoleh dapat dilihat pada Tabel 5. Berdasakan Tabel 5 dapat diketahui bahwa nilai benchmarking dari UD. Bu Sulasmi di bawah nilai Omah Jenang. Oleh karena itu, nilai target didapatkan dari benchmarking pesaing (Omah Jenang).

Perbaikan respon teknis ditunjukkan oleh nilai gap. Gap merupakan selisih nilai dari kedua perusahaan, semakin negatif nilai gap maka semakin besar skala prioritas untuk diperbaiki (Sutojo et al., 2011). Nilai gap tertinggi terletak pada perawatan mesin/alat produksi. Hal ini dikarenakan pesaing telah memiliki mesin yang digunakan dalam pengolahan jenang, sedangkan UD. $\mathrm{Bu}$ Sulasmi menggunakan alat produksi manual. Adanya mesin dalam membuat perusahaan membuat perawatan yang lebih terjadwal agar mesin tetap bersih dan tidak mengalami gangguan. 
Tabel 4. Urutan Prioritas

\begin{tabular}{llcc}
\hline No. & \multicolumn{1}{c}{ Respon Teknis } & Bobot Respon & Prioritas \\
\hline 1 & Perancangan desain kemasan & 591,13 & 1 \\
2 & Teknis pengolahan yang tepat & 431,87 & 2 \\
3 & Teknik pengemasan yang tepat & 409,91 & 3 \\
4 & Penyediaan informasi kualitas pada kemasan & 407,10 & 4 \\
5 & $\begin{array}{l}\text { Pengaturan komposisi bahan baku dan bahan } \\
\text { pendukung }\end{array}$ & 355,34 & 5 \\
6 & $\begin{array}{l}\text { Pemilihan bahan baku dan bahan pendukung } \\
\text { yang berkualitas }\end{array}$ & 336,93 & 6 \\
7 & Teknis penyimpanan yang tepat & & 7 \\
8 & Penetapan harga jual & 288,51 & 8 \\
9 & Perawatan mesin/alat produksi & 221,76 & 9 \\
\hline
\end{tabular}

Sumber: Data Primer Diolah (2017)

Tabel 5. Nilai Benchmarking dan Target

\begin{tabular}{|c|c|c|c|c|c|}
\hline No. & Atribut & $\begin{array}{l}\text { UD.Bu } \\
\text { Sulasmi }\end{array}$ & $\begin{array}{l}\text { Omah } \\
\text { Jenang }\end{array}$ & Gap & Target \\
\hline 1 & $\begin{array}{l}\text { Pemilihan bahan baku dan bahan } \\
\text { pendukung yang berkualitas }\end{array}$ & 3.23 & 3,66 & $-0,43$ & 3,66 \\
\hline 2 & Teknis pengolahan yang tepat & 3,24 & 3,70 & $-0,46$ & 3,70 \\
\hline 3 & $\begin{array}{l}\text { Pengaturan komposisi bahan baku dan } \\
\text { bahan pendukung }\end{array}$ & 3,28 & 3,65 & $-0,37$ & 3,65 \\
\hline 4 & Teknik pengemasan yang tepat & 3,01 & 3,82 & $-0,81$ & 3,82 \\
\hline 5 & Teknis penyimpanan yang tepat & 3,28 & 3,79 & $-0,51$ & 3,86 \\
\hline 6 & Penetapan harga jual & 2,84 & 3,57 & $-0,73$ & 3,57 \\
\hline 7 & Perancangan desain kemasan & 2,97 & 3,69 & $-0,72$ & 3,69 \\
\hline 8 & Perawatan mesin/alat produksi & 3,09 & 3,98 & $-0,89$ & 3,98 \\
\hline 9 & $\begin{array}{l}\text { Penyediaan informasi kualitas pada } \\
\text { kemasan }\end{array}$ & 2,69 & 3,49 & $-0,80$ & 3,49 \\
\hline
\end{tabular}

Sumber: Data Primer Diolah (2017) 


\section{KESIMPULAN}

Berdasarkan penelitian yang telah dilakukan, dapat disimpulkan, yaitu:

1. Atribut produk yang yang menjadi prioritas utama kebutuhan konsumen UD. Bu Sulasmi adalah tercantumnya tanggal kadaluwarsa (CR10) dengan nilai kepentingan akhir 0,0796, desain kemasan dengan nilai 0.0714 , dan kesesuaian berat bersih jenang dengan informasi yang tertera pada kemasan dengan nilai 0.0665 .

2. Perbaikan yang dapat dilakukan oleh perusahaan adalah dengan melakukan perancangan desain kemasan yang lebih menarik dengan mencantumkan informasi kualitas pada kemasan.

\section{DAFTAR PUSTAKA}

Andayani, A., A.S. Sukardi, dan A. Suryani. 2015. Desain produk makanan ringan untuk ibu hamil dengan menggunakan quality function deployment (QFD). E-Jurnal Agroindustri Indonesia. 4(1):22523324.

Anonim. 2013. Kabupaten Blitar. http://bappeda.jatimprov.go.id/bapped a/wpcontent/uploads/potensi-kabkota-2013/kab-blitar-2013.pdf. Diunduh tanggal 23 November 2016.

Asmaul, S.M., A.R. Mulyarto, S. Nurkhasanah. 2011. Analisis positioning keripik kentang dengan pendekatan metode multi dimensional scalling di Kota Batu. AGROINTEK. 5(2):98-106.

Astuti, E.D. 2013. Perilaku konsumtif dalam membeli barang pada ibu rumah tangga di Kota Samarinda. EJurnal Psikologi. 1(2):148-156.

Chan, L.K., H.P. Kao, and M.L. Wu. 1999. Rating the importance of customer needs in quality function deployment by fuzzy and entropy methods. International Journal of Production Research. 37(11):2499-2518.
Chen, S. 2007. Using quality function deployment to llan curricula in higher education. J. of Human Resource and Adult Learning. 3(2):39-49.

Efendi, Z. 2007. Penerapan quality function deployment (QFD) untuk peningkatan kinerja industri kecil bakso sapi berdasarkan kepuasan pelanggan. J. Sains Peternakan Indonesia. 2(2): 85-91.

Harris, H. dan M. Fadli. 2014. Penentuan umur simpan (shelf life) pindang seluang (Rasbora $s p$ ) yang dikemas menggunakan kemasan vakum dan tanpa vakum. J. Saintek Perikanan. 9(2):53-62.

Jaelani, E. 2012. Perencanaan dan pengembangan produk dengan quality function deployment (QFD). J. Sains Manajemen \& Akuntansi. 4(1):1-12.

Kiswanto, H., Susanto, dan W. Nur. 2013. Penilaian kinerja karyawan dengan metode fuzzy multi criteria decision making menggunakan microsoft visual C\# 2010 dan SQL server 2008 R2 (studi kasus PT. ISW Semarang). Jurnal Transit. 1(1):5-12.

Kahraman, C., E.E. Kerre,, and F.T. Bozbura. 2012. Uncertainty modeling in knowledge engineering and decision making. Proceedings of the $10^{\text {th }}$ International FLINS Conference. Agustus 2012. Turkey.

Kosasih, W., I.A. Soenandi, dan E. Celsia. 2013. Aplikasi QFD untuk pengembangan produk wafer. J. Teknik dan Ilmu Komputer. 2(7):258269.

Latief, W.A. 2011. Analisis faktor psikologis konsumen dan pengaruhnya terhadap keputusan pembelian. J. Administrasi Indonesia. 1(1):70-139.

Liu, H.T. 2009. The Extension of fuzzy QFD: from product planning to party deployment. Expert System with Applications. 36(8):11131-11144.

Maulida, R., E. Gunadhi, dan N. Priyatna. 2013. Pengembangan produk permen susu karamel untuk meningkatkan produktivitas usaha berdasarkan 
kebutuhan konsumen. J. Kalibrasi STT Garut. 11(1):1-9.

Mulyadi, A.F. 2011. Studi kelayakan pendirian unit pengolahan gula semut dengan pengolahan sistem reprosesing pada skala industri menengah di Kabupaten Blitar. Prosiding Lokakarya Nasional Pemberdayaan Potensi Keluarga Tani untuk Pengentasan Kemiskinan. Juli 2011. Malang.

Murni, F. Arifan, dan Z. Abidin. 2015. Peningkatan produktivitas industri jenang dan krasikan melalui penerapan mesin pengaduk otomatis termodifikasi di Karangluh Kecamatan Salam Magelang. Jurnal TRAKSI. 15(2):45-51.

Nursalam. 2008. Konsep dan Penerapan Metodologi Penelitian Ilmu Keperawatan. Penerbit Salemba Medika. Jakarta. 276 hlm.

Nusa, M.I., M. Fuadi, dan W.A.P. Pulungan. 2012. Studi pembuatan dodol pisang (Musa paradisiacal L). J. Agrium. 17(3):227-235.

Saidani, B. dan S. Arifin. 2012. Pengaruh kualitas produk dan Kualitas Layanan terhadap Kepuasan Konsumen dan Minat Beli Ranch Market. J. Riset Manajemen Sains Indonesia (JRMSI) 3(1):1-22.

Suryaningrat, I. B., Djumarti, E. Ruriana, dan I. Kurniawati. 2010. Application of quality function deployment (QFD) method for quality improvement of corn noodle product. J. Agroteknologi. 4(1):8-17.

Syamsudin, S., F. Wajdi, A.N. Praswati. 2015. Desain kemasan makanan KUB Sukarasa di Desa wisata organik Sukorejo Sragen. J. Manajemen dan Bisnis. 19(2):181-188.

Sutojo, T., E. Mulyanto, V. Suhartono. 2011. Kecerdasan buatan. Andi Offset. Yogyakarta.

Tutuhatunewa, A. 2010. Aplikasi metode quality function deployment dalam pengembangan produk air minum kemasan. J. ARIKA. 4(1):11-19.

Yunal, V.O. dan R. Indrayani. 2013. Analisa pengaruh motivasi berwirausaha dan inovasi produk terhadap pertumbuhan kerajinan gerabah di Lombok Barat. J. AGORA. 1(1):1-11.

Wawolumaja, R. dan M. Rudianto. 2012. Rekayasa Kualitas: QFD (Quality Function Deployment). Diktat Kuliah TI. Fakultas Teknik Universitas Kristen Maranatha. Bandung.

Zagloel, Y.M., M. dan R. Nurcahyo. 2013. TQM: Manajemen Kualitas Total dalam Perspektif Teknik Industri. PT Indeks. Jakarta. 